\title{
Complex effects of different types of acid rain on root growth of Quercus acutissima and Cunninghamia lanceolata saplings
}

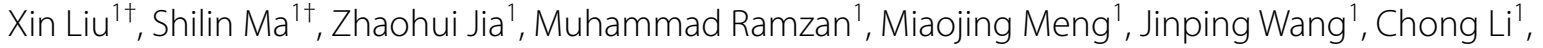 \\ Yinlong Zhang ${ }^{2}$ and Jinchi Zhang ${ }^{1 *}$
}

\begin{abstract}
Background: Soil acidification caused by acid rain (AR) can damage plant roots, which in turn negatively impacts plant health. In response to changing AR types, research efforts to elucidate their specific impacts on plants have become intense.

Methods: For this study, we investigated the effects of simulated sulfuric, nitric, and mixed AR on the root systems of Quercus acutissima Carr. and Cunninghamia lanceolata (Lamb.) Hook. under different acidity levels.

Results: As the AR S/N ratio and pH decreased, the height growth rate (HGR), basal diameter growth rate (DGR), total root length (TRL) and total root surface area (TRS) of C. lanceolata decreased, whereas the TRL and TRS of Q. acutissima remained the same. When the $\mathrm{NO}_{3}{ }^{-}$concentration in AR was increased, the root activity, superoxide dismutase (SOD) and catalase (CAT) activities of $C$. lanceolata roots revealed a downward trend; however, the root activity of Q. acutissima and the peroxidase (POD) activity of $C$. lanceolata roots revealed an upward trend. Further, redundant analysis and structural equation models indicated that $\mathrm{AR} \mathrm{pH}$ had a greater impact on the HGR of Q. acutissima than that of $C$. lanceolata, while the impact of the AR S/N ratio on C. lanceolata growth rates was greater than that of $Q$. acutissima.

Conclusions: Our results suggested that the root systems of different tree species had variable responses to $A R$, and the AR S/N ratio was an important factor affecting plant root growth. This might facilitate new strategies for the cultivation and protection of plantations in the future.
\end{abstract}

Keywords: Sulfuric and nitric acid rain, Root growth, Root morphology, Root activity, Antioxidant enzyme activity

\section{Introduction}

Over the last few decades, in conjunction with its rapid economic growth, China has established the largest plantation area in the world (Tang et al. 2015). Quercus acutissima Carr. and Cunninghamia lanceolata (Lamb.) Hook. are the dominant tree species in China, which

\footnotetext{
*Correspondence: zhang8811@njfu.edu.cn

${ }^{+}$Xin Liu and Shilin Ma contributed equally to this work

${ }^{1}$ Co-Innovation Center for Sustainable Forestry in Southern China,

Jiangsu Province Key Laboratory of Soil and Water Conservation

and Ecological Restoration, Nanjing Forestry University, 159 Longpan

Road, Nanjing 210037, Jiangsu, China

Full list of author information is available at the end of the article
}

have important economic and ecological value, with multiple uses beyond timber (Kang et al. 2018; Zhang et al. 2004). However, with increasing acid rain (AR), many plantations suffer from its deleterious effects (Sun et al. 2016).

$A R$ is a progressively serious environmental issue caused by anthropogenic urbanization and industrialization (Zhang et al. 2017), which not only has negative impact on ecosystems, but also significantly threatens human health and survival (Ma et al. 2021). In addition to Europe and North America, China is the third largest AR-afflicted region worldwide (Ren et al. 2018). The primary sources of AR include sulfur dioxide $\left(\mathrm{SO}_{2}\right)$ and 
nitrogen oxide $\left(\mathrm{NO}_{\mathrm{x}}\right)$ (Lv et al. 2014), which dissolve in water to form sulfuric acid rain (SAR) and nitric acid rain (NAR) (Zhang et al. 2007). The exact composition of $A R$ varies from region to region, among which SAR was once the main type of AR in China due to coal combustion (Liu et al. 2020; Ma et al. 2019). In view of the more stringent control of sulfur emissions from factories since 1990 (Chan and Yao 2008), in conjunction with increased vehicular exhaust emissions caused by rapid economic development (Liu et al. 2018c), the SAR in China is progressively transforming to NAR (Liu et al. 2020).

Root systems facilitate plant growth via mechanical support, nutrient foraging, gas exchange, through the recruitment of beneficial microbes, etc. (Bardgett et al. 2014), which allows plants to endure various biological and abiotic stresses (Saleem et al. 2018), such as salinity, acidity, drought, and pests. Concurrently, root density and distribution are intimately linked to the soil environment, where root density influences the growth of aboveground plant components (Simpson et al. 2020). However, broadleaf and coniferous species possess unique root characteristics, thus, their tolerance for and responses to AR are variable (Ren et al. 2018). Research shows that AR increases the accumulation of reactive oxygen species in roots (Ju et al. 2017b), reduces root activities (Liu et al. 2018b), limits the utilization of nutrients and inhibits root growth (Zhang et al. 2016a) by altering soil chemistry and cation adsorption (Xu and Ji 2001). Besides, as the AR in China shifts from SAR to NAR, its $\mathrm{NO}_{3}{ }^{-}$concentration gradually increased, which can fertilize plants to some extent (Sparks 2009). However, these higher $\mathrm{NO}_{3}{ }^{-}$concentrations can affect the nitrogen metabolism associated with genes and associated proteins (Liu et al. 2013), further influences amino acid biosynthesis and disrupts the metabolic balance between nitrogen and carbon (Zhang et al. 2020). Thus, the influences of different types of AR on plants are complex and variable. Accordingly, a growing number of researchers have committed to the study of different types of AR, with most of them focusing on the recovery of acidified soil (Liu et al. 2020), decomposition of litter (Liu et al. 2017), microbial communities (Li et al. 2021) and the physiology of aboveground components (Yao et al. 2016), while few investigations have set their focus on root physiology (Huang et al. 2019; Liu et al. 2018b). Although we have previously explored the fine root biomass and fine root elements of subtropical plantation in response to different types of AR (Liu et al. 2018c), the data remain limited in regard to the complex effects of different types of AR on the root growth of Q. acutissima and C. lanceolata under pot experiment.

To investigate the specific impacts of different types of AR on Q. acutissima (broadleaf) and C. lanceolata (conifer) root growth, AR simulation tests using potted plants were developed. Our objective was to explore the effects of different $\mathrm{S} / \mathrm{N}$ ratios and acidities on the root systems of these two species, which included total root length, total root surface area, average root diameter, root activity, and the activities of antioxidant enzymes in contrast to a control. In accordance with earlier studies, we proposed our hypotheses as follows: (1) AR inhibits the root growth of $Q$. acutissima and C. lanceolata saplings; (2) this inhibition is exacerbated by higher concentrations of $\mathrm{NO}_{3}^{-}$; (3) the root systems of different tree species have variable responses to higher AR acidity and $\mathrm{NO}_{3}{ }^{-}$concentrations.

\section{Methods}

\section{Plant material and treatments}

This study was conducted from March 2015 to April 2016 in a greenhouse at the Xiashu Ecological Station $\left(31^{\circ} 7^{\prime} \mathrm{N}, 119^{\circ} 12^{\prime} \mathrm{E}\right)$ of Nanjing Forestry University, in Jiangsu Province, China. The research samples included 1-year old Q. acutissima and C. lanceolata seedlings of uniform height. The average height of the Q. acutissima saplings was $31.23 \pm 2.63 \mathrm{~cm}$, with ground diameters of $2.75 \pm 0.53 \mathrm{~cm}$, whereas the average height of the $C$. lanceolata saplings was $27.15 \pm 1.33 \mathrm{~cm}$, with ground diameters of $5.03 \pm 0.28 \mathrm{~cm}$. Following the preparation of plastic pots $(\varnothing 20 \mathrm{~cm} \times 25 \mathrm{~cm}$ high) that contained yellow-brown soil (as described by the Chinese Soil Classification System) (Li et al. 2020) with a pH of $6.31 \pm 0.01$, which was collected from nearby plantations, we transplanted the saplings into the pots.

The physical and chemical soil properties were as follows: total carbon content $(0.78 \mathrm{~g} / \mathrm{kg})$; total nitrogen content $(0.05 \mathrm{~g} / \mathrm{kg})$; total phosphorus content $(0.5 \mathrm{~g} / \mathrm{kg})$; total potassium content $(14.18 \mathrm{~g} / \mathrm{kg})$; ammonium nitrogen content $(15.3 \mathrm{mg} / \mathrm{kg})$; available phosphorus content (34.2 mg/kg); available potassium content $(121.39 \mathrm{mg} /$ $\mathrm{kg})$; and electric conductivity $(0.24 \mathrm{mS} / \mathrm{cm})$. Following transplantation, the saplings were allowed 2 months of recovery time, during which they were hydrated with distilled water. Additionally, the indoor environmental conditions of the greenhouse were as follows: temperature $18-35{ }^{\circ} \mathrm{C}$, relative humidity $40-80 \%$, light/dark period $14 / 10 \mathrm{~h}$, light intensity $700-1000 \mathrm{~mol} /\left(\mathrm{m}^{2} \mathrm{~s}\right)$.

After 2 months recovery time, 192 uniform saplings of tree species (with only slight differences) were selected for the simulation experiment. By mixing $0.5 \mathrm{~mol} / \mathrm{l}$ $\mathrm{H}_{2} \mathrm{SO}_{4}$ and $0.5 \mathrm{~mol} / \mathrm{l} \mathrm{HNO}_{3}$ in different proportions, 16 treatments including $15 \mathrm{AR}$ treatments and a control group (ck) were established. The specific formulations were as follows: ck (distilled water, $\mathrm{pH} 7.0), \mathrm{S} 1$ ( $\mathrm{S} / \mathrm{N}=1: 0$, $\mathrm{pH}=4.5), \quad \mathrm{S} 2 \quad(\mathrm{~S} / \mathrm{N}=1: 0, \quad \mathrm{pH}=3.5), \quad \mathrm{S} 3 \quad(\mathrm{~S} / \mathrm{N}=1: 0$, $\mathrm{pH}=2.5), \quad \mathrm{S} 4 \quad(\mathrm{~S} / \mathrm{N}=5: 1, \quad \mathrm{pH}=4.5), \quad \mathrm{S} 5 \quad(\mathrm{~S} / \mathrm{N}=5: 1$, 
$\mathrm{pH}=3.5), \quad \mathrm{S} 6 \quad(\mathrm{~S} / \mathrm{N}=5: 1, \quad \mathrm{pH}=2.5), \quad \mathrm{S} 7 \quad(\mathrm{~S} / \mathrm{N}=1: 1$, $\mathrm{pH}=4.5), \quad \mathrm{S} 8 \quad(\mathrm{~S} / \mathrm{N}=1: 1, \quad \mathrm{pH}=3.5), \quad \mathrm{S} 9 \quad(\mathrm{~S} / \mathrm{N}=1: 1$, $\mathrm{pH}=2.5), \quad \mathrm{S} 10 \quad(\mathrm{~S} / \mathrm{N}=1: 5, \quad \mathrm{pH}=4.5), \quad \mathrm{S} 11 \quad(\mathrm{~S} / \mathrm{N}=1: 5$, $\mathrm{pH}=3.5), \quad \mathrm{S} 12 \quad(\mathrm{~S} / \mathrm{N}=1: 5, \mathrm{pH}=2.5), \quad \mathrm{S} 13 \quad(\mathrm{~S} / \mathrm{N}=0: 1$, $\mathrm{pH}=4.5), \mathrm{S} 14(\mathrm{~S} / \mathrm{N}=0: 1, \mathrm{pH}=3.5)$, and $\mathrm{S} 15(\mathrm{~S} / \mathrm{N}=0: 1$, $\mathrm{pH}=2.5$ ).

The total simulated AR was $670.38 \mathrm{~mm}$, whereas the monthly simulated AR was $55.865 \mathrm{~mm}$ according to the average annual precipitation of $1117.29 \mathrm{~mm}$ and AR frequency of $60 \%$ (Liu et al. 2017). Based on the $314 \mathrm{~cm}^{2}$ pot area, the simulated monthly AR volume for each pot was $1754.16 \mathrm{ml}$. Starting in May 2015, each sapling was sprayed with $438.54 \mathrm{ml}$ of simulated AR four times per month until April 2016 (Liu et al. 2018b; Ma et al. 2021). On April 30, 2016, 80 saplings of each tree species were selected for the determination of each index.

\section{Growth measurement}

The sapling heights, from the bases of the stems to the terminal buds, were quantified using a tape measure. The stem basal diameters were measured using a Vernier caliper at the bases of the stems. The initial measurements were taken on April 30, 2015, and the final measurements were obtained on April 30, 2016. The relative growth rates of the basal diameter and height were determined by the equations described by Ma et al. (2021).

\section{Determination of root morphology}

The roots of each seedling were rinsed with deionized water and scanned using an Epson Expression 12000XL scanner (Japan). The images were analyzed using WinRHIZO (WinRHIZO Pro2016) to determine the total root length (TRL), total root surface area (TRS), and average root diameter (AD) (Zhou et al. 2019).

\section{Malondialdehyde content of roots}

Malondialdehyde (MDA) was extracted from root tissues using 5\% trichloroacetic acid (TCA) solution and reacted with a $0.6 \%$ thiobarbituric acid (TBA) solution and was expressed as $\mu \mathrm{g} / \mathrm{g}$. The specific method was followed as described by Wang et al. (2020).

\section{Root activity}

The root activity was measured using the triphenyl tetrazolium chloride (TTC) method, and expressed as the deoxidization capacity $(\mu \mathrm{g} / \mathrm{g} \mathrm{h})$. The specific method was in reference to Zhang et al. (2015).

\section{Antioxidant activities}

To prepare a crude enzyme extract, $2-3 \mathrm{~g}$ of root tissues were placed in a $5-\mathrm{ml}$ frozen phosphate buffer $(50 \mathrm{mM}$, $\mathrm{pH}$ 7.8) for homogenization. An ultraviolet spectrophotometer was employed to elucidate the activities of superoxide dismutase (SOD), peroxidase (POD) and catalase (CAT) and were expressed as unit $\mathrm{mg} /$ protein min (Ma et al. 2021). The specific methods were described by Khan et al. (2017).

\section{Statistical analysis}

One-way ANOVA was employed to investigate variations in the growth rates and root traits of Q. acutissima and C. lanceolata among the treatments. Moreover, twoway ANOVA was utilized to assess the main impacts and interactivity of the $\mathrm{AR} S / \mathrm{N}$ ratio and $\mathrm{pH}$ on the growth rates and root traits (SPSS 26.0 Inc., Chicago, Ill., USA).

Redundant analysis (RDA) was utilized to reveal the relationships between the simulated $\mathrm{AR} \mathrm{pH}, \mathrm{S} / \mathrm{N}$ ratio, growth rate, root morphologies, and root physiological properties, which were visualized using Canoco 5.0 (Microcomputer Power, Ithaca, NY, USA). AMOS 22.0 (SPSS Inc., Chicago, Ill., USA) was employed to develop structural equation models to test whether the AR S/N ratio and $\mathrm{pH}$ directly or indirectly impacted the growth rates and root morphologies through the modification of the physiological properties of the roots.

\section{Results \\ Growth rate}

The AR pH significantly impacted the height and basal diameter growth rates of $Q$. acutissima and C. lanceolata $(p<0.05)$, which was the same for the AR $S / N$ ratio $(p<0.05)$, except for the height growth rate of $Q$. acutissima. In contrast to $C$. lanceolata, the interaction of the $\mathrm{AR} S / \mathrm{N}$ ratio and $\mathrm{pH}$ significantly impacted the growth of $Q$. acutissima $(p<0.05)$ (Fig. 1).

When the AR pH was 3.5, the height growth rates of Q. acutissima treated with S2, S8, and S14 were lower than the ck $(p<0.05)$. As the $\mathrm{pH}$ dropped to 2.5 , the S6, S9, S12, and S15 height growth rates of Q. acutissima were also below the ck $(p<0.05)$ (Fig. 1A). However, the basal diameter growth rate of $Q$. acutissima treated with S4 and S13 were greater than the ck $(p<0.05)$ (Fig. 1C). Further, the height growth rates of $C$. lanceolata initially increased and then decreased with lower $\mathrm{pH}$, where only the S13 and S15 treatments were below the ck $(p<0.05)$ (Fig. 1B), while the basal diameter growth rate continued to decrease. All the other treatments were below the control except for S1, S4, S5, and S7 treatments $(p<0.05)$ (Fig. 1D). Both the height and basal diameter growth rates of $C$. lanceolata exhibited a downward trend as the proportion of nitrogen was increased, except for the height growth rates of the S10, S11, and S12 treatments, and basal diameter growth rate of the S5 treatment (Fig. 1B, D). 


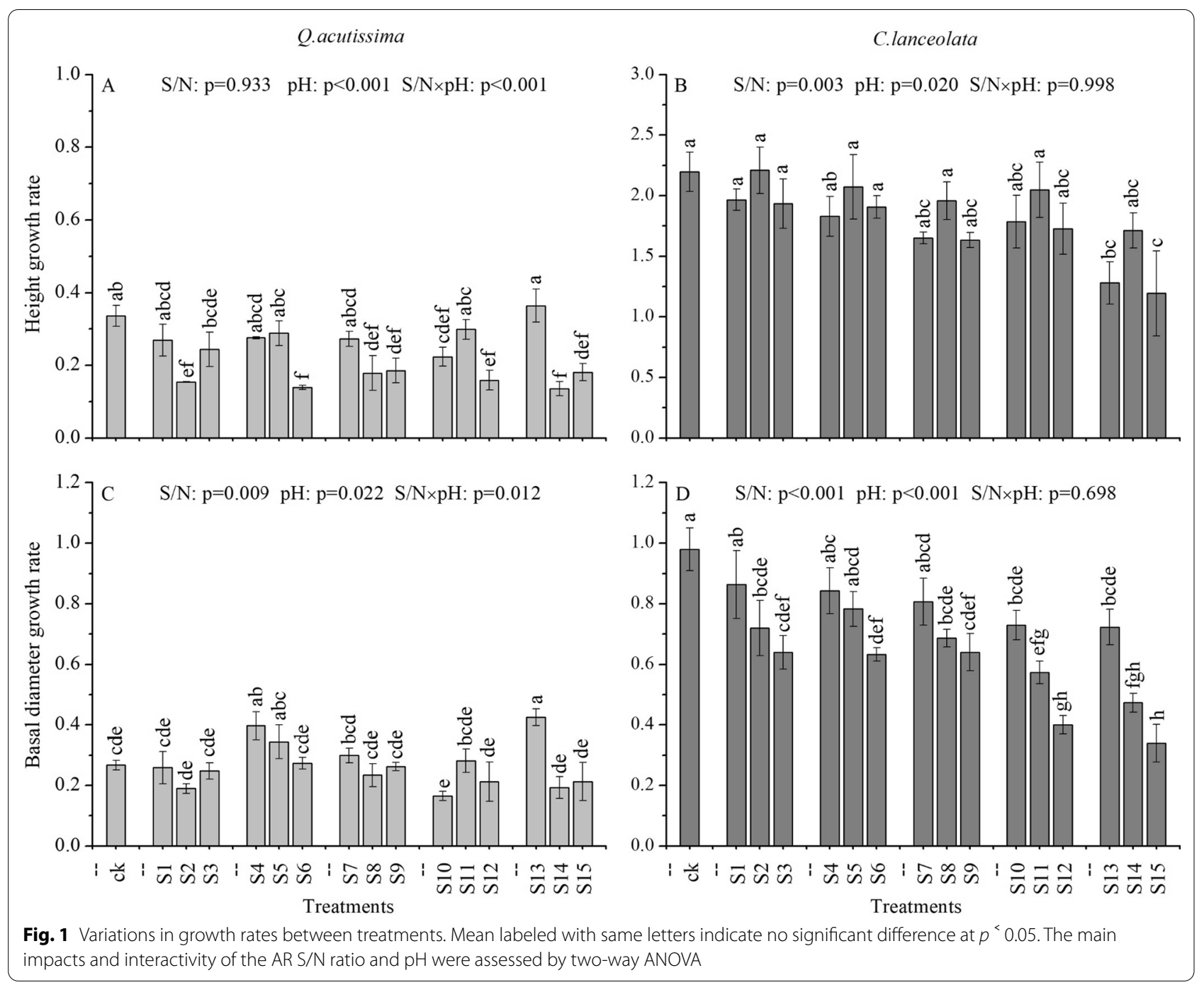

\section{Root morphology}

Compared with the ck, the total root length, total root surface area, and root average diameter varied with the AR treatments (Fig. 2). The AR $\mathrm{S} / \mathrm{N}$ ratio significantly affected the total root length of Q. acutissima $(p<0.05)$, while AR $\mathrm{pH}$ had a strong effect on total root surface area $(p<0.05)$. The responses of the total root length and total root surface area of $C$. lanceolata to the AR $\mathrm{S} / \mathrm{N}$ ratio and $\mathrm{pH}$ were notable $(p<0.05)$. However, the AR $\mathrm{S} / \mathrm{N}$ ratio, $\mathrm{pH}$, and their interactions had negligible effects on the root average diameter of the two species.

With higher AR nitrogen proportions, the total root length and total root surface area of the two species exhibited variable decreasing tendencies. Moreover, the total root length and surface area of both species decreased as the AR acidity increased, except for the total root length of the S10 and S11 treatments for Q. acutissima. In addition, the total root length of $Q$. acutissima under the S12, S14, and S15 treatments and total root surface area under the S8, S9, S12, S14 and S15 treatments were below the ck $(p<0.05)$ (Fig. 2A, C). When the $\mathrm{AR} \mathrm{pH}$ was 3.5 or 2.5 , most of the total root length and total root surface area of C. lanceolata were lower than those of the ck, except for the S5 and S11 treatments $(p<0.05)$ (Fig. 2B, D). The root average diameter of the two tree species differed insignificantly between treatments (Fig. 2E, F).

\section{Malondialdehyde content of roots}

The AR $\mathrm{S} / \mathrm{N}$ ratio and $\mathrm{pH}$ influenced the malondialdehyde (MDA) content of Q. acutissima and C. lanceolata to a considerable degree $(p<0.05)$, and we observed significant interactive effects $(p<0.05)$. With higher AR acidity, the MDA content of Q. acutissima increased while that of $C$. lanceolata initially increased and then decreased, except when the $\mathrm{S} / \mathrm{N}$ ratio was $0: 1$. When the 


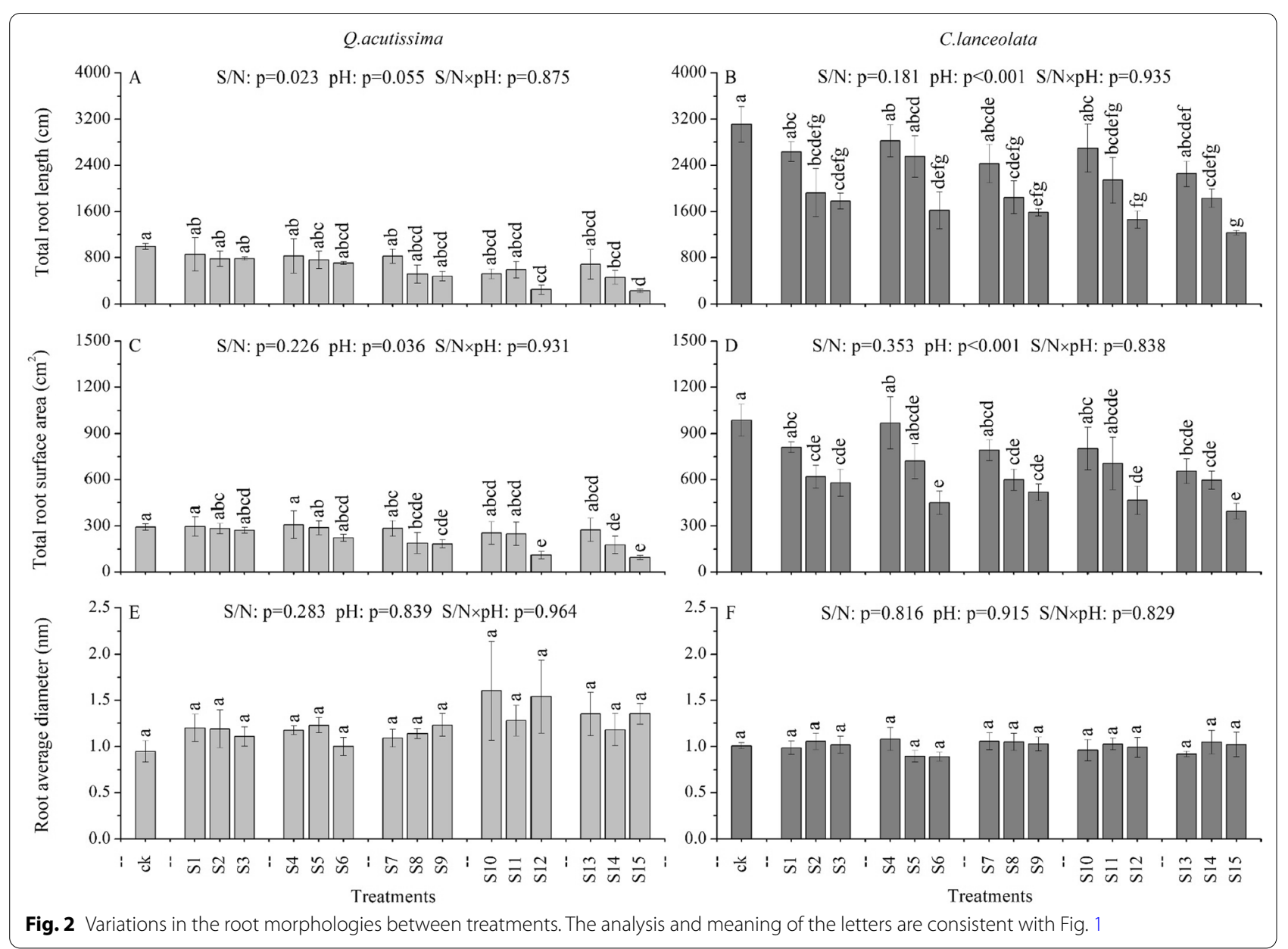

AR S/N ratios were 1:0 and 5:1, the MDA contents of $Q$. acutissima and C. lanceolata under all AR treatments, except for $\mathrm{S} 4$ treatment, exceeded the corresponding ck $(p<0.05)$. However, when the AR S/N ratios were 1:5 and $0: 1$, only the MDA content of $Q$. acutissima under the S12 treatment, and the MDA contents of C. lanceolata under the S11 and S15 treatments were higher than the corresponding ck $(p<0.05)$ (Fig. 3).

\section{Root activity}

The AR S/N ratio and $\mathrm{pH}$ significantly affected the root activities of Q. acutissima and C. lanceolata $(p<0.05)$ and demonstrated considerable interactive effects $(p<0.05)$. With the increased proportion of nitrogen in AR, the root activity of $Q$. acutissima showed a gradually increasing trend, while that of $C$. lanceolata was the converse. When the AR S/N ratios were 1:0 and 5:1, the root activity of $Q$. acutissima exhibited a variable tendency to decrease after increasing with higher acidity, while that of C. lanceolata was reduced. When the AR S/N ratio was $1: 1$, the root activity of $Q$. acutissima decreased continuously with higher acidity, while that of C. lanceolata initially increased and then decreased. When the AR $\mathrm{S} / \mathrm{N}$ ratios were $1: 5$ and $0: 1$, the root activity of the two species initially increased and then decreased with higher acidity. Furthermore, when the AR S/N ratio was 0:1 and $\mathrm{pH}$ was 3.5 , the root activity of Q. acutissima was higher than that of the ck $(p<0.05)$ (Fig. 4).

\section{Antioxidant enzyme activities}

The $\mathrm{S} / \mathrm{N}$ ratio of the AR had no significant effect on the SOD activity of $Q$. acutissima; however, its interaction with the $\mathrm{pH}$ significantly influenced its activity $(p<0.05)$. Most of the SOD activity of Q. acutissima roots did not change significantly under AR treatments compared with the ck. When the $\mathrm{S} / \mathrm{N}$ ratio was changed from 1:5 to $0: 1$, the SOD activity of $Q$. acutissima roots decreased significantly under the $\mathrm{pH} 2.5$ treatment $(p<0.05)$. The main and interactive effects of the AR $\mathrm{S} / \mathrm{N}$ ratio and $\mathrm{pH}$ on the SOD activity of $C$. lanceolata roots reached significant levels $(p<0.05)$. With higher $\mathrm{AR} \mathrm{NO}_{3}{ }^{-}$concentrations, 


\section{Q.acutissima}

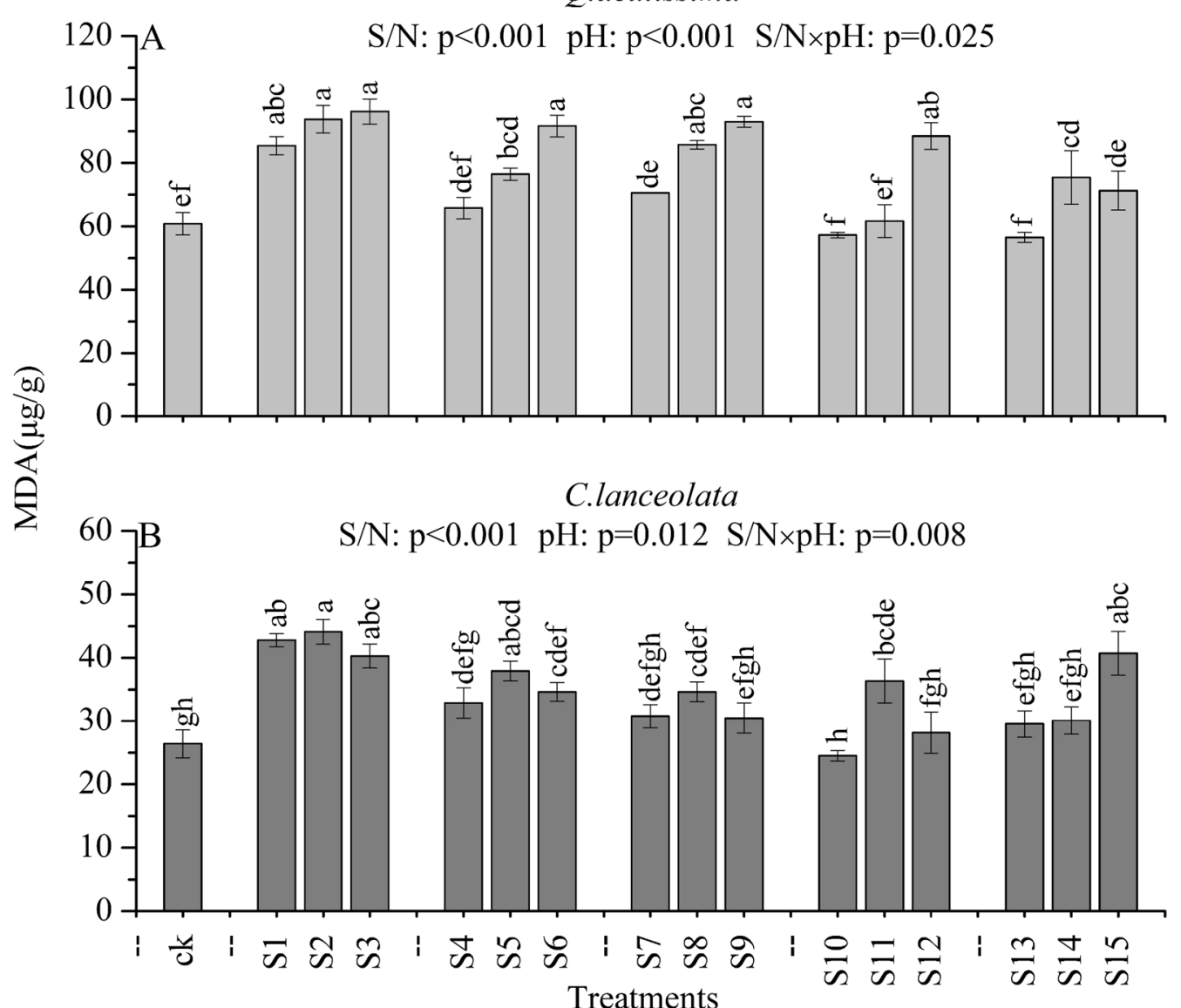

Fig. 3 Variations in root MDA contents between treatments. The analysis and meaning of the letters are consistent with Fig. 1

the SOD activity of $C$. lanceolata roots showed a downward trend (Fig. 5A, B).

There was no significant difference in the POD activity between the $\mathrm{S} / \mathrm{N}$ ratio and $\mathrm{pH}$ in the $\mathrm{Q}$. acutissima roots under the AR treatments. However, in contrast to the ck, the root POD activity of Q. acutissima was higher $(p<0.05)$ under most AR treatments, except when the AR $\mathrm{pH}$ was 4.5 and the $\mathrm{S} / \mathrm{N}$ ratios were $1: 0$ and 1:1; when the AR pH was 3.5 and the $\mathrm{S} / \mathrm{N}$ ratios were $1: 5$ and 5:1; and when the AR pH was 3.5 and the $\mathrm{S} / \mathrm{N}$ ratio was $0: 1$. Furthermore, when the $\mathrm{S} / \mathrm{N}$ ratio was altered from $1: 5$ to $0: 1$, the POD activity of $Q$. acutissima roots decreased significantly under the $\mathrm{pH} 2.5$ treatment $(p<0.05)$. The POD activity of $C$. lanceolata roots had a significant response to the AR S/N ratio and its interaction with $\mathrm{pH}(p<0.05)$, and gradually increased with higher $\mathrm{AR} \mathrm{NO}_{3}{ }^{-}$concentrations. The POD activity of $C$. lanceolata roots under NAR stress was higher than the ck $(p<0.05)$, except when the $\mathrm{S} / \mathrm{N}$ ratio was $1: 5$ and the $\mathrm{pH}$ was 3.5 (Fig. $5 \mathrm{C}, \mathrm{D}$ ).

The main and interactive effects of the $\mathrm{S} / \mathrm{N}$ ratio and $\mathrm{pH}$ of the AR on the CAT activities of Q. acutissima and
C. lanceolata roots were significant $(p<0.05)$. When the $\mathrm{S} / \mathrm{N}$ ratio was altered from $1: 5$ to $0: 1$, the CAT activity of $Q$. acutissima roots decreased significantly under each $\mathrm{pH}$ treatment $(p<0.05)$. When the AR $\mathrm{pH}$ was 4.5 , and the AR S/N ratio changed from 5:1 to $1: 5$, the CAT activity of $Q$. acutissima roots initially decreased and then increased, while the opposite was the case when the AR $\mathrm{pH}$ was 3.5 and 2.5. Further, the CAT activity of C. lanceolata roots revealed the variable tendency of decreasing with higher $\mathrm{NO}_{3}{ }^{-}$concentrations in the $\mathrm{AR}$ under all $\mathrm{pH}$ levels (Fig. 5E, F).

\section{Redundant analysis results}

Using the $\mathrm{AR} \mathrm{NO}_{3}{ }^{-}$concentrations, $\mathrm{pH}$, and the physiological characteristics of roots as explanatory variables, redundant analysis was performed on the sapling growth rates and root morphologies. Among them, Axis 1 explained $41.68 \%$ of the variation in the Q. acutissima dataset and $48.54 \%$ of the variation in the C. lanceolata dataset, whereas Axis 2 accounted for $1.55 \%$ of the 


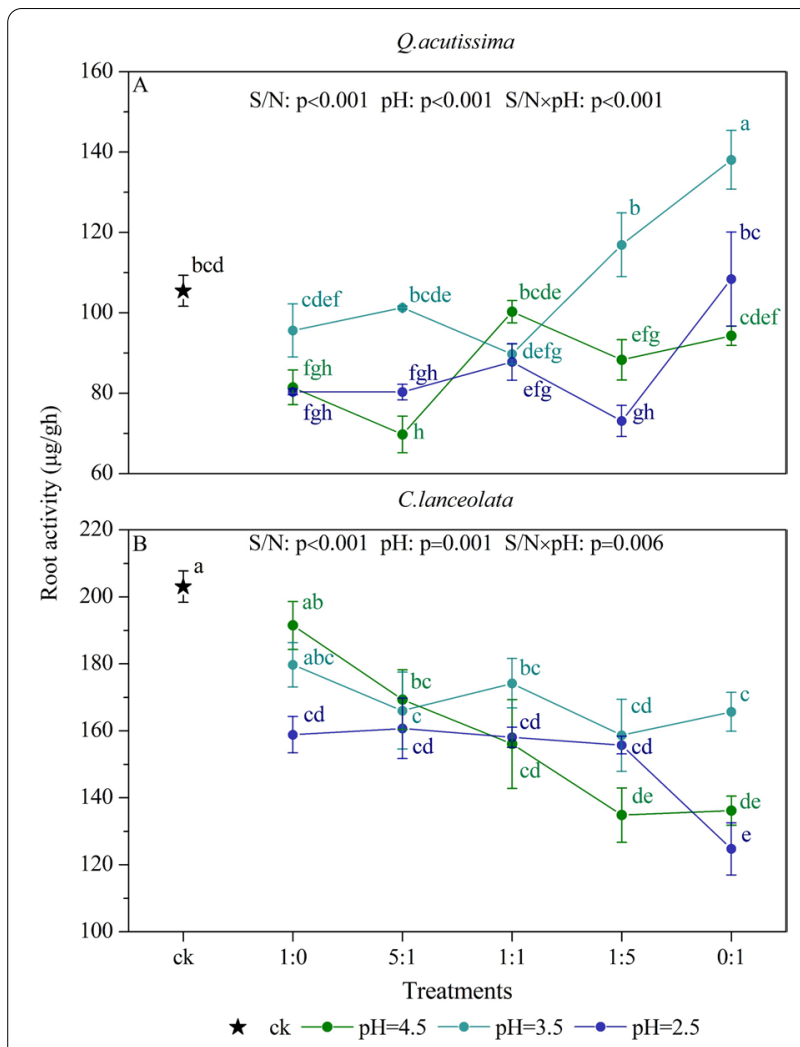

Fig. 4 Variations in the root activities (TTC) between treatments. Different ratios represent the AR S/N ratio and different colors represent $\mathrm{AR} \mathrm{pH}$. The analysis and the meaning of the letters are consistent with Fig. 1

variation in the Q. acutissima dataset, and $3.78 \%$ of the variation in the C. lanceolata dataset.

As depicted in Fig. 6A, a high total root surface area, total root length with height growth rate, and basal diameter growth rate were found at the left side of coordinate axis, which were related to the $\mathrm{AR} \mathrm{NO}_{3}{ }^{-}$concentration and $\mathrm{pH}$. The CAT, POD, SOD, and root average diameter increased along the $y$-axis, whereas the TTC and MDA decreased. As shown in Fig. 6B, a high total root length, total root surface area, and basal diameter growth rate were found in the left quadrant, which were related to the AR pH. The CAT, SOD, TTC, MDA, and height growth rate decreased along the $y$-axis, whereas the POD and AR $\mathrm{NO}_{3}{ }^{-}$concentration increased.

\section{Structural equation model results}

The structural equation modeling of $Q$. acutissima and C. lanceolata was estimated by Amos (Fig. 7). Model A and Model $\mathrm{B}$ were the structural equation models of the effects of $\mathrm{NO}_{3}{ }^{-}$and $\mathrm{pH}$ on the aboveground growth rates and root morphologies of Q. acutissima and C. lanceolata, respectively.
Model A revealed that the direct effects of the $\mathrm{AR} p H$ on the $Q$. acutissima sapling height growth rate $(0.46$, $p<0.001)$ and total root surface area $(0.39, p<0.01)$ were significant, while the $\mathrm{AR} \mathrm{NO}_{3}{ }^{-}$concentration had a significant direct effect on the total root length $(-0.20$, $p<0.01)$ and total root surface area $(-0.37, p<0.01)$ (Fig. 7A). Due to the indirect influences of induced root system property changes, the standardized total effects of the $\mathrm{AR} \mathrm{pH}$ on the Q. acutissima sapling height growth rate and basal diameter growth rate were 0.508 and 0.299 , respectively. The total effect of the $\mathrm{AR} \mathrm{NO}_{3}{ }^{-}$concentration on the $Q$. acutissima sapling height growth rate and basal diameter growth rate was 0.000 and -0.094 , respectively (Table 1).

Model B showed that the direct effects of the AR pH on the C. lanceolata sapling basal diameter growth rate $(0.66, p<0.001)$ and total root surface area $(0.69$, $p<0.001)$ were significant, while the $\mathrm{AR} \mathrm{NO}_{3}{ }^{-}$concentration had a substantial direct impact on the basal diameter growth rate $(-0.51, p<0.01)$ (Fig. $7 \mathrm{~B})$. Due to the indirect effects of induced changes to root system properties, the standardized total effect of the $\mathrm{AR} \mathrm{pH}$ on the $C$. lanceolata sapling height growth rate and basal diameter growth rate was 0.027 and 0.617 , respectively. The total effects of the $\mathrm{AR} \mathrm{NO}_{3}{ }^{-}$concentrations on the C. lanceolata sapling height and basal diameter growth rates were -0.482 and -0.533 , respectively (Table 1 ).

\section{Discussion}

Plants utilize $\mathrm{NO}_{3}{ }^{-}$as an important strategy to facilitate their absorption of nitrogen (Shi et al. 2014; Wang et al. 2019). Although the strong oxidation of $\mathrm{NO}_{3}{ }^{-}$can damage plant cell structures (Mo et al. 2008), the transformation of nitrogen can produce certain benefits (in terms of fertilization) for plant growth (Ouyang et al. 2008; Qiu et al. 2015). Consequently, various types of AR have complex and variable impacts on the root systems of plants.

\section{Complex effects of different types of AR on growth rates of different tree species}

The relative growth rates of the basal diameters and heights of plants are critical indicators that reflect their growth under environmental stress (Liu et al. 2018a). This argument supported our first hypothesis that AR will inhibit plant growth and lead to plant poisoning, when $\mathrm{pH}$ values attain a certain damaging threshold (Ju et al. 2017b). Since deciduous species are more sensitive to AR than evergreen species (Du et al. 2017), C. lanceolata exhibited a higher acid tolerance than did Q. acutissima. This was most clearly illustrated by the AR with the highest acidity ( $\mathrm{pH} 2.5$ ), which significantly inhibited the height growth rate of $Q$. acutissima, while the inhibitory 


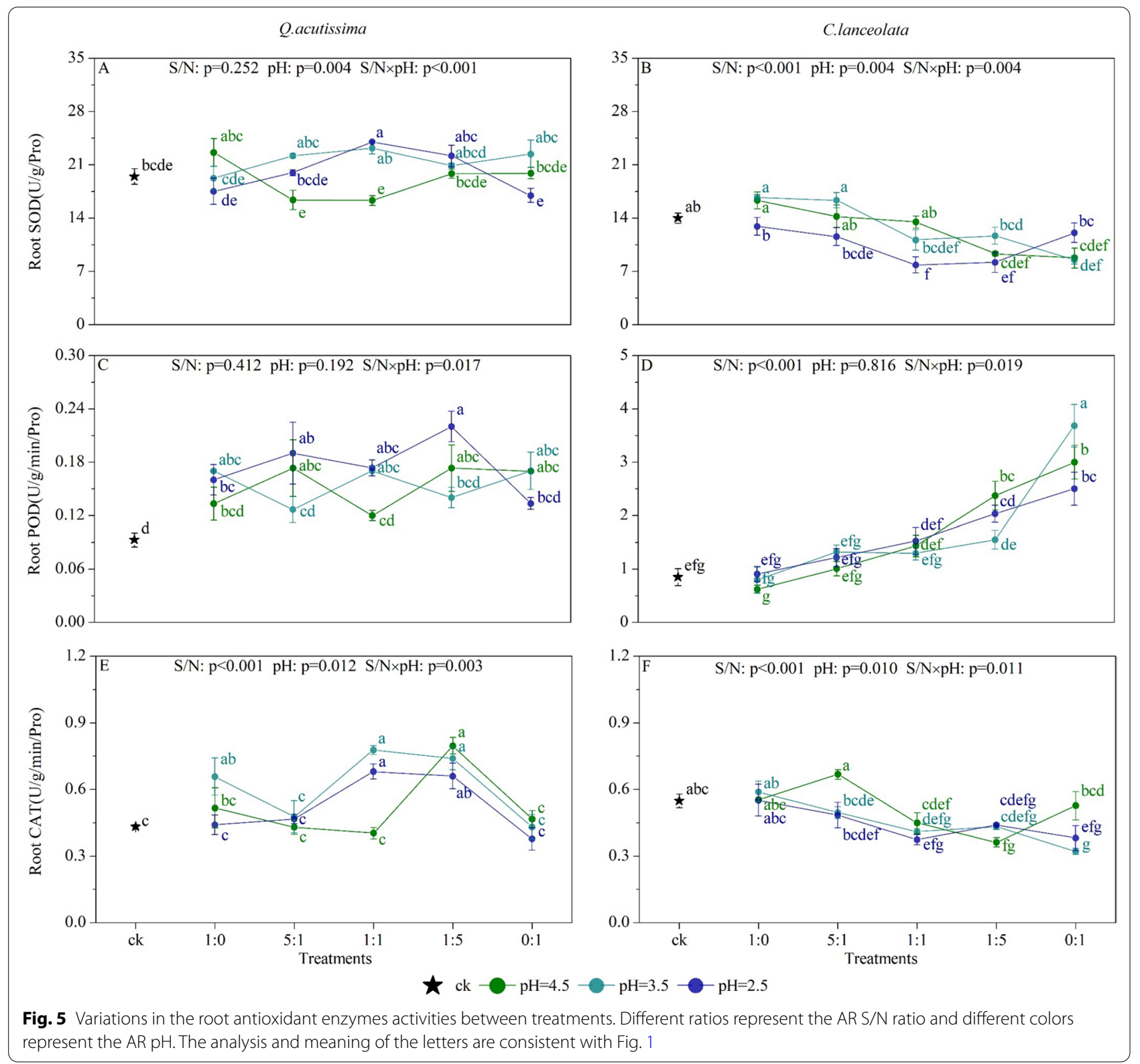

effect of high acidity AR on the height growth rate of $C$. lanceolata was reflected only in pure NAR.

Researchers found that different tree species had variable nitrogen uptake characteristics (Rollwagen and Zasoski 1988), where most conifers had a preference for ammonium nitrogen uptake in contrast to hardwoods (Kronzucker and Siddiqi 1997; Malagoli et al. 2000). This explained why $\mathrm{NO}_{3}{ }^{-}$did not have a fertilizing effect on the basal diameter growth rate of $C$. lanceolata compared with $Q$. acutissima. Further, in contrast to previous research on broadleaf trees (Chen et al. 2013; Lee et al. 2006), we found that highly acidic NAR had a more potent inhibitory effect on the basal diameter growth rate of $C$. lanceolata than did SAR and MAR. Since the hydroxyl exchange capacity of $\mathrm{NO}_{3}{ }^{-}$was lower than that of $\mathrm{SO}_{4}{ }^{2-}$, NAR promoted soil acidification to a greater degree than did SAR (Lindberg et al. 1990). Combined with the nitrogen absorption characteristics of tree species, we inferred that the NAR induced stronger $\mathrm{H}^{+}$ stress on the aboveground growth of $C$. lanceolata than on Q. acutissima.

\section{Complex effects of different types of AR on root morphologies of different tree species}

The inhibition of plant growth due to AR not only affects the aboveground plant components that are directly 

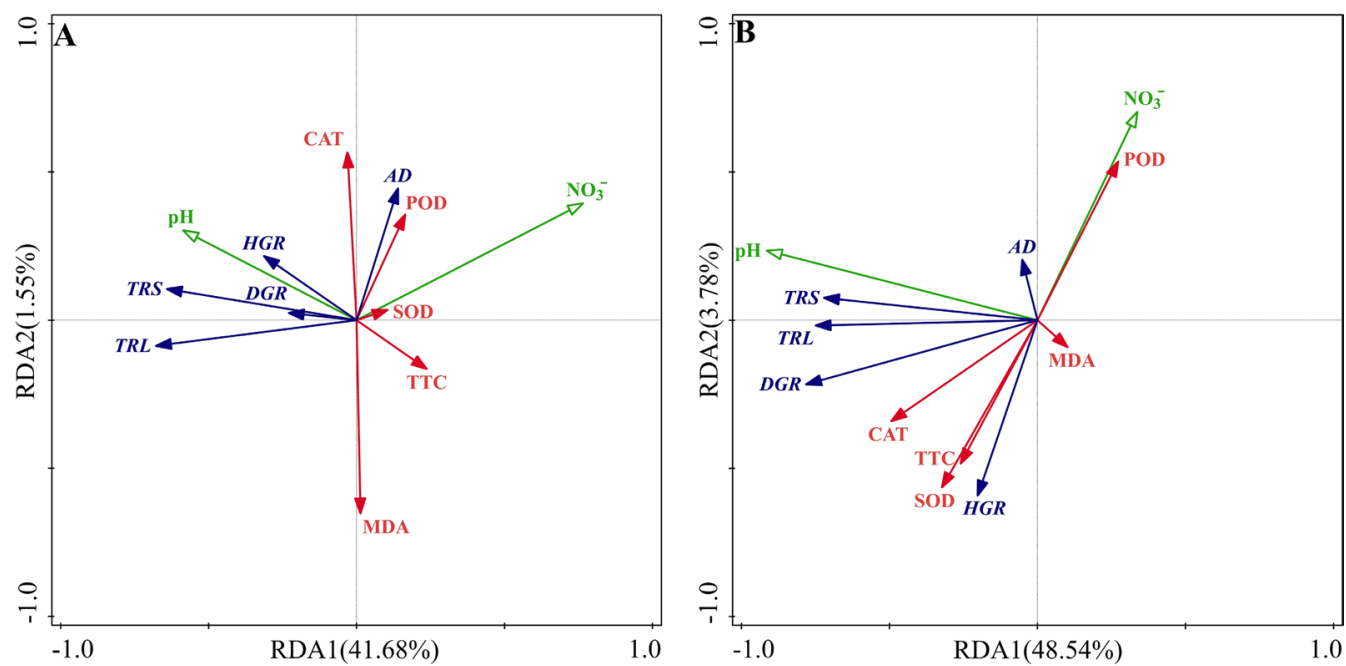

Fig. 6 Redundant analysis of simulated AR, growth rates, root morphologies, and root physiological properties. The angles and lengths of the arrows indicate the direction and strength of the relationship of simulated $A R$, growth rates, root morphologies, and root physiological properties. $\mathbf{A}$ Redundant analysis of Q. acutissima; $\mathbf{B}$ redundant analysis of $C$. lanceolata. $\mathrm{RDA}$, redundant analysis; $\mathrm{pH}, \mathrm{AR} \mathrm{pH}, \mathrm{NO}_{3}^{-}$, the concentration of $\mathrm{NO}_{3}{ }^{-}$in $A R ; H G R$, height growth rate; DGR, basal diameter growth rate; TRL, total root length; TRS, total root surface area; AD, root average diameter; MDA, root malondialdehyde content; $T T C$, root activity; SOD, superoxide dismutase activity in root; POD, peroxidase activity in root; CAT, catalase activity in root

(See figure on next page.)

Fig. 7 Structural equation model of $\mathrm{NO}_{3}{ }^{-}$and $\mathrm{pH}$ effects on aboveground tree growth rate and root morphologies. A Structural equation model of $Q$. acutissima $\left(X^{2}=12.033 ; d f=10, p=0.283>0.05 ; G F I=0.951>0.900 ; R M S E A=0.068<0.080\right)$. B Structural equation model of $C$. lanceolata $\left(X^{2}=12.627 ; d f=11, p=0.318>0.05 ; G F I=0.951>0.900 ;\right.$ RMSEA $\left.=0.058<0.080\right)$. Numbers on lines are standardized path coefficients. The widths of lines indicate the strength of the causal influence. Solid lines represent the direct effects on plant growth rates and root growth, dotted lines represent the effects on root physiologies. $\mathrm{pH}, \mathrm{AR} \mathrm{pH} ; \mathrm{NO}_{3}{ }^{-}$, the concentration of $\mathrm{NO}_{3}{ }^{-}$in $\mathrm{AR} ; \mathrm{HGR}$, height growth rate; DGR, basal diameter growth rate; TRL, total root length; TRS, total root surface area; TTC, root activity; SOD, activity of superoxide dismutase in root; POD, activity of peroxidase in root; CAT, activity of catalase in root

exposed to AR, but also leads to the degradation of soil fertility and increases the vulnerability of plants to toxic metals (Du et al. 2017). Root morphology (e.g., root length, surface area, number of root tips, etc.) can reflect the growth of plant roots under environmental stress (Forino et al. 2012), such as acidity. Our research revealed that all highly acidic $\mathrm{AR}(\mathrm{pH}=2.5)$ significantly inhibited the total root length and total surface area of $C$. lanceolata; however, the inhibitory effects of highly acidic AR on the total root length and total surface area of $Q$. acutissima was primarily reflected in the NAR. Not only did our experimental results prove our first hypothesis, previous studies on soybean and rice root systems also confirmed the inhibitory effects of highly acidic AR on root morphologies (Sun et al. 2013; Zhang et al. 2016a).

Consistent with our second hypothesis and research on Horsfieldia mer (Huang et al. 2019), but contradictory to some research (Ju et al. 2020), the inhibition of simulated AR on the root growth of the two tree species under study increased with higher $\mathrm{NO}_{3}{ }^{-}$concentrations.
Studies have shown that excessive nitrogen supplies can inhibit root growth and elongation, which verified our results above. Furthermore, although the NAR reduced the mineralization of soil carbon, nitrogen, and phosphorus (Liu et al. 2018b), and had a particular fertilizing effect on plants, the degree of soil acidification was increased due to $\mathrm{NO}_{3}{ }^{-}$, and the roots were significantly stressed by acid and aluminum poisoning (Liu et al. 2018c). Additionally, the potent oxidative properties of $\mathrm{NO}_{3}{ }^{-}$caused additional damage to plant roots (Mo et al. 2008).

\section{Complex effects of different types of AR on the root physiology of different tree species}

The lipid peroxidation product malondialdehyde (MDA) can serve as an indicator of oxidative damage (Wang et al. 2007); thus, it may be employed to elucidate fluctuations in plant growth and functionality under environmental stress (Sánchez-Pardo et al. 2012). In alignment with a previous study (Xia et al. 2017), most of the MDA 

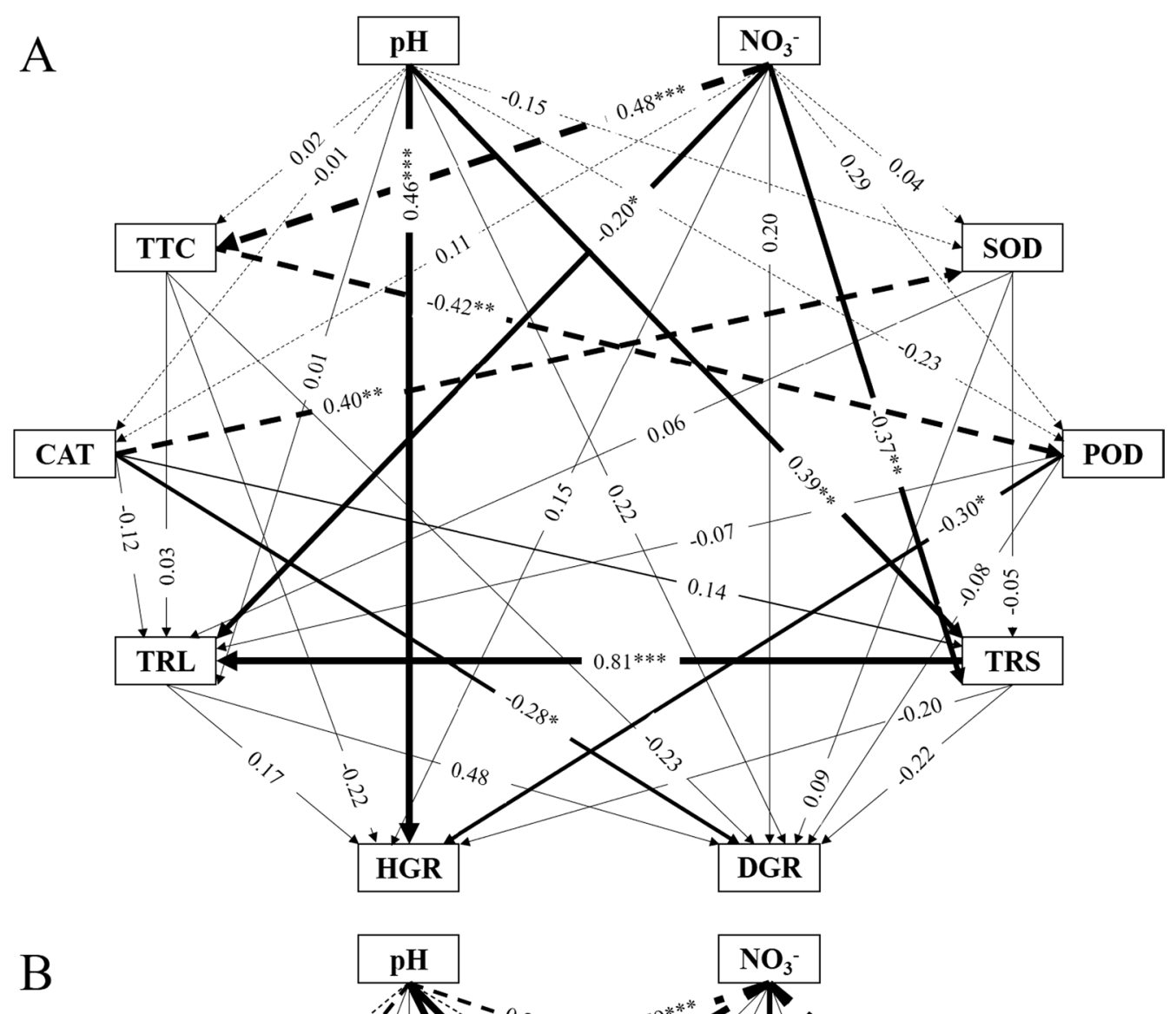
Table 1 Direct, indirect, and total impact tables of $\mathrm{AR} \mathrm{pH}$ and $\mathrm{NO}_{3}{ }^{-}$concentrations on height growth rate and basal diameter growth rate of $Q$. acutissima and C. lanceolata saplings

\begin{tabular}{crrrrr}
\hline & \multicolumn{2}{c}{ Q. acutissima } & & & \multicolumn{2}{l}{ C. lanceolata } \\
\cline { 3 - 3 } & HGR & DGR & & HGR & \multicolumn{1}{c}{ DGR } \\
\hline $\mathrm{NO}_{3}{ }^{-}$ & & & & \\
SDE & 0.148 & 0.204 & & -0.241 & -0.513 \\
SIE & -0.148 & -0.299 & & -0.241 & -0.020 \\
STE & 0.000 & -0.094 & & -0.482 & -0.533 \\
$\mathrm{pH}$ & & & & \\
SDE & 0.458 & 0.217 & & -0.277 & 0.662 \\
SIE & 0.050 & 0.081 & & 0.303 & -0.045 \\
STE & 0.508 & 0.299 & & 0.027 & 0.617 \\
\hline
\end{tabular}

This table shows the standardized direct, indirect, and total effects of the concentration of $\mathrm{NO}_{3}{ }^{-}$in $\mathrm{AR}$ and $\mathrm{AR} \mathrm{pH}$ on the height and basal diameter growth rates of $Q$. acutissima and $C$. lanceolata saplings

$\mathrm{pH}, \mathrm{AR} \mathrm{pH} ; \mathrm{NO}_{3}{ }^{-}$, the concentration of $\mathrm{NO}_{3}{ }^{-}$in $\mathrm{AR} ; \mathrm{HGR}$, height grow rate; $\mathrm{DGR}$ basal diameter growth rate; SDE, standardized direct effects; SID, standardized indirect effects; STE, standardized total effects

content of Q. acutissima and C. lanceolata roots under AR stress exceeded that of their corresponding $\mathrm{ck}$, which further verified that AR has destructive effects on the physiology and growth of plant roots. A study on the resistance of Arabidopsis to different types of AR found that the SAR treatment had the highest MDA content (Qiao et al. 2018). This was consistent with the MDA trend of $Q$. acutissima roots in our study. However, the high acidity of NAR significantly increased the MDA content of C. lanceolata roots. The tree species formed the characteristic of the selective absorption of nitrogen during the process of long-term adaptation. Tree species growing in neutral or alkaline soils are more predisposed to absorb $\mathrm{NO}_{3}{ }^{-}-\mathrm{N}$ (Zhang and Bai 2003), which relieves NAR stress damage to a certain degree.

The differences in AR tolerance caused by the nitrogen absorption strategies of tree species were also reflected in our research on root activity. With higher $\mathrm{NO}_{3}{ }^{-}$concentrations in the simulated $\mathrm{AR}$, the root activities of Q. acutissima increased, while for C. lanceolata they decreased. Since different tree species have variable responses to nitrogen deposition (Thomas et al. 2009), and $Q$. acutissima is sensitive to nitrogen absorption (Ma et al. 2021; Yu et al. 2019), the fertilization effect of $\mathrm{NO}_{3}{ }^{-}$ in our study was exhibited most prominently in the $Q$. acutissima root systems, while the positive effects of fertilization by $\mathrm{NO}_{3}{ }^{-}$on $C$. lanceolata roots were lower than the negative effects of $\mathrm{H}^{+}$stress. Root activity reflects the metabolism of root systems and is an important physiological indicators for the assessment of water and nutrient uptake (Islam et al. 2007). Most studies on the effects of AR on root activity revealed that they decreased under lower AR pH (Liang and Wang 2013; Sun et al. 2013; Zhang et al. 2016b). Surprisingly, under the influence of pure NAR, the root activities of Q. acutissima and C. lanceolata treated with $\mathrm{pH} 3.5$ were significantly higher than the other $\mathrm{pH}$ treatments. Due to the significant addition of $\mathrm{NO}_{3}{ }^{-}$in the $\mathrm{NAR}$, the nitrogen metabolism in plant roots were improved (Qiao et al. 2018) and their threshold tolerance for acidity was increased, while the acidityinduced stress within this tolerance range had a certain growth-promoting effect.

To alleviate the damage from reactive oxygen species (ROS) that is inflicted on plants under stress, they generate multiple antioxidant enzymes, such as SOD, POD, and CAT (Kazemi et al. 2010). The generation and accumulation of ROS are also related to particular tree species (Chen et al. 2013). In our study, when the AR $(\mathrm{pH}=2.5)$ type changed from 1:5 NAR to pure NAR, the activities of SOD, POD, and CAT in the Q. acutissima root system were significantly decreased. On the one hand, highly acidic NAR initiates a significant increase of $\mathrm{H}^{+}$in plant cells (Liang et al. 2015). Excessive $\mathrm{H}^{+}$will lead to the superabundant accumulation of ROS, such as hydrogen peroxide and superoxide anions, which will in turn induce oxidative stress in plants (Ahmad et al. 2010; Gill and Tuteja 2010). On the other hand, excessive $\mathrm{NO}_{3}{ }^{-}$ accelerates soil acidification (Lindberg et al. 1990), and its strong oxidation will also damage plant organelles (Mo et al. 2008). Therefore, under the influence of two these aspects, the ROS level of the Q. acutissima root system exceeded the standard, cell structures were seriously damaged, and the activities of the antioxidant system were inhibited. Compared with $Q$. acutissima roots, the antioxidant enzyme activities of $C$. lanceolata roots were more closely related to the $\mathrm{NO}_{3}{ }^{-}$concentration of $\mathrm{AR}$. The POD oxidation reaction is dominant in protecting plant cells from the influence of high oxygen concentrations, when cellular oxygen concentrations become too high (Bezerril Fontenele et al. 2017). The POD activity of C. lanceolata roots under NAR stress was significantly higher than that of the ck in our study, which demonstrated that the impact of NAR on the oxidative stress of C. lanceolata roots was primarily reflected through increased intercellular oxygen levels. Furthermore, consistent with previous work (Qiao et al. 2018), the CAT activity of the MAR treatment in this study was significantly higher than that of SAR at $\mathrm{pH} 2.5$. However, when the AR S/N was shifted from 5:1 to $1: 5$, the change of CAT activity in Q. acutissima roots at $\mathrm{pH} 4.5$ was opposite to that of $\mathrm{pH} 3.5$ and 2.5. We attributed this to the acid tolerance threshold of $Q$. acutissima, where the $\mathrm{AR}$ at $\mathrm{pH} 4.5$ was still within its tolerance range. However, with higher $\mathrm{NO}_{3}{ }^{-}$concentration, its strong oxidizing properties still boosted the accumulation of active 
oxygen (Ahmad et al. 2010), which in turn increased its CAT activity at a $\mathrm{S} / \mathrm{N}$ ratio of $1: 5$.

\section{Variations between tree species in response to different types of AR}

Various plants have different tolerances for AR (Ren et al. 2018), and studies have found that the abundance of $\mathrm{H}^{+}$ caused by AR is the main factor that threatens the growth of trees. The trees absorb $\mathrm{H}^{+}$into plant cells through roots, which induces changes in intracellular free radicals that have adverse effects on root growth (Zhou et al. 2020). Consistent with the above results, redundancy analysis and structural equation modeling showed that $\mathrm{AR} \mathrm{pH}$ had a positive standardized total effect on growth rates of $Q$. acutissima and C. lanceolata (the higher the acidity of the AR, the greater the negative impact). In contrast to C. lanceolata, AR pH had a strong correlation with the height growth rate of $Q$. acutissima, and primarily affected seedling height growth through direct influence. As a broadleaved tree species, Q. acutissima leaves are more vulnerable and sensitive to AR (Du et al. 2017), as excessive hydrogen ions can severely inhibit its photosynthesis (Du et al. 2020), and directly lead to the slow growth of seedling height. However, since C. lanceolata is a tree species that grows well in acidic soil, it has higher acid tolerance (Zhang and Bai 2003), which weakens the influence of AR pH to a certain extent. This result partially supports our third hypothesis mentioned above.

With the change in AR types, the $\mathrm{NO}_{3}{ }^{-}$concentration of AR has gradually attracted increased attention (Liu et al. 2019). Redundancy analysis and structural equation model indicated that the $\mathrm{NO}_{3}{ }^{-}$concentrations in AR had a negative standardized indirect effect on the growth rates of both $Q$. acutissima and C. lanceolata. This revealed that excessive $\mathrm{AR} \mathrm{NO}_{3}{ }^{-}$concentration can inhibit root activity, destroy antioxidant systems through its strong oxidation, and then weaken the height growth of seedlings (Liu et al. 2018b). However, in contrast to $Q$. acutissima, the $\mathrm{NO}_{3}{ }^{-}$concentrations in AR had a strong correlation with the height growth rate of C. lanceolata. In addition to its negative indirect effects, the $\mathrm{NO}_{3}{ }^{-}$concentrations in AR also directly inhibited the height growth of $C$. lanceolata seedlings. As discussed above, this may be related to the nitrogen utilization characteristics of trees (Thomas et al. 2009). Excessive $\mathrm{NO}_{3}{ }^{-}$concentrations in AR affects the nitrogen absorption and utilization in C. lanceolata, however, they have a certain fertilizing effect on Q. acutissima. This result further supported our third hypothesis. In short, our results indicated that changing AR types further complicate the challenges faced in the development of different plantations.
Furthermore, this study analyzed only the responses of the root systems of Q. acutissima and C. lanceolata to various types of simulated AR under brief potting tests; thus, there remains a lack of long-term natural environmental research. For future studies, we aim to establish a long-term field experiment combined with root turnover, to further explore the impacts of different simulated AR types on the root systems and growth of different tree species.

\section{Conclusion}

During simulated AR stress, as the concentration of $\mathrm{NO}_{3}{ }^{-}$increased in AR, the inhibitory effect of AR on the root growth of $Q$. acutissima and C. lanceolata saplings gradually exacerbated. The root systems of $Q$. acutissima and C. lanceolata saplings had variable responses to higher AR acidity and $\mathrm{NO}_{3}{ }^{-}$concentrations. Meanwhile, the AR pH had a direct potent inhibition on the height growth rate of Q. acutissima in contrast to $C$. lanceolata, while the $\mathrm{AR} S / \mathrm{N}$ ratio affected the growth rate of $C$. lanceolata to a greater degree than $Q$. acutissima by directly inhibiting and indirectly impacting the physiological attributes of the roots. In brief, highly acidic AR and elevated $\mathrm{NO}_{3}{ }^{-}$concentrations had the capacity to alter the physiological characteristics of roots. Although the degree of these changes and their positive or negative effects may vary with tree species, they ultimately inhibit the growth of trees. Compared with C. lanceolata, Q. acutissima was less affected by AR with high $\mathrm{NO}_{3}{ }^{-}$concentrations.

\section{Abbreviations}

SAR: Sulfuric acid rain; NAR: Nitric acid rain; MAR: Mixed acid rain; RDA: Redundant analysis; SEM: Structural equation model; SDE: Standardized direct effects; SID: Standardized indirect effects; STE: Standardized total effects; HGR: Height growth rate; DGR: Basal diameter growth rate; TRL: Total root length; TRS: Total root surface area; AD: Root average diameter; MDA: Malondialdehyde content; TTC: Root activity; SOD: Superoxide dismutase; POD: Peroxidase; CAT: Catalase.

\section{Acknowledgements}

We'd like to thank Professor Frank Boehm from Lakehead University for his language editing.

\section{Authors' contributions}

$X L$ and $S M$ wrote the manuscript. JZ and $X L$ conceived the experiments. $X L, S M, Z J, M R, M M, J W$, and $C L$ conducted the experiments. $X L$ and $S M$ interpreted data. JZ and $Y Z$ provided financial support. $X L$ and SM revised the manuscript. All authors read and approved the final manuscript.

\section{Funding}

This research was funded by the Jiangsu Province Science Foundation for Youths (BK20200785), China Postdoctoral Science Foundation (2018M642260), the National Special Fund for Forestry Scientific Research in the Public Interest (Grant No. 201504406), Priority Academic Program Development of Jiangsu Higher Education Institutions (PAPD) and Jiangsu Agriculture Science and Technology Innovation Fund (Grant No. CX (17)1004). 


\section{Availability of data and materials}

The datasets used and/or analyzed during the current study are available from the corresponding author on reasonable request.

\section{Declarations}

\section{Ethics approval and consent to participate}

Not applicable.

\section{Consent for publication}

Not applicable.

\section{Competing interests}

The authors declare that they have no competing interests.

\section{Author details}

${ }^{1}$ Co-Innovation Center for Sustainable Forestry in Southern China, Jiangsu Province Key Laboratory of Soil and Water Conservation and Ecological Restoration, Nanjing Forestry University, 159 Longpan Road, Nanjing 210037, Jiangsu, China. ${ }^{2}$ Co-Innovation Center for Sustainable Forestry in Southern China, Nanjing Forestry University, 159 Longpan Road, Nanjing 210037, Jiangsu, China.

Received: 4 August 2021 Accepted: 6 December 202

Published online: 21 January 2022

\section{References}

Ahmad P, Jaleel CA, Salem MA, Nabi G, Sharma S (2010) Roles of enzymatic and nonenzymatic antioxidants in plants during abiotic stress. Crit Rev Biotechnol 30:161-175

Bardgett RD, Mommer L, De Vries FT (2014) Going underground: root traits as drivers of ecosystem processes. Trends Ecol Evol 29:692-699

Bezerril Fontenele NM, Otoch MLO, Gomes-Rochette NF, Sobreira ACM, Barreto $A$, de Oliveira FDB et al (2017) Effect of lead on physiological and antioxidant responses in two Vigna unguiculata cultivars differing in Pb-accumulation. Chemosphere 176:397-404

Chan CK, Yao X (2008) Air pollution in mega cities in China. Atmos Environ 42:1-42

Chen J, Wang WH, Liu TW, Wu FH, Zheng HL (2013) Photosynthetic and antioxidant responses of Liquidambar formosana and Schima superba seedlings to sulfuric-rich and nitric-rich simulated acid rain. Plant Physiol Biochem 64:41-51

Du E, Dong D, Zeng X, Sun Z, Jiang X, de Vries W (2017) Direct effect of acid rain on leaf chlorophyll content of terrestrial plants in China. Sci Total Environ 605-606:764-769

Du J, Qv M, Zhang Y, Cui M, Zhang H (2020) Simulated sulfuric and nitric acid rain inhibits leaf breakdown in streams: a microcosm study with artificial reconstituted fresh water. Ecotoxicol Environ Saf 196:110535

Forino L, Castiglione MR, Bartoli G, Balestri M, Andreucci A, Tagliasacchi AM (2012) Arsenic-induced morphogenic response in roots of arsenic hyperaccumulator fern Pteris vittata. J Hazard Mater 235-236:271-278

Gill SS, Tuteja N (2010) Reactive oxygen species and antioxidant machinery in abiotic stress tolerance in crop plants. Plant Physiol Biochem 48:909-930

Huang J, Wang H, Zhong Y, Huang J, Fu X, Wang L et al (2019) Growth and physiological response of an endangered tree, Horsfieldia hainanensis Merr., to simulated sulfuric and nitric acid rain in southern China. Plant Physiol Biochem 144:118-126

Islam E, Yang X, Li T, Liu D, Jin X, Meng F (2007) Effect of Pb toxicity on root morphology, physiology and ultrastructure in the two ecotypes of Elsholtzia argyi. J Hazard Mater 147:806-816

Ju S, Wang L, Yin N, Li D, Wang Y, Zhang C (2017a) Silicon alleviates simulated acid rain stress of Oryza sativa L. seedlings by adjusting physiology activity and mineral nutrients. Protoplasma 254:2071-2081

Ju S, Yin N, Wang L, Zhang C, Wang Y (2017b) Effects of silicon on Oryza sativa L. seedling roots under simulated acid rain stress. PLoS ONE 12:e0173378
Ju S, Wang Y, Wang N, Chen M (2020) The effects of silicon and different types of acid rain on root growth and physiology activity of Oryza sativa L. seedlings. Bull Environ Contam Toxicol 105:967-971

Kang J, Lee H, Lim H, Lee W (2018) Identification of potential metabolic markers for the selection of a high-yield clone of Quercus acutissima in clonal seed orchard. Forests 9:116

Kazemi N, Khavari-Nejad RA, Fahimi H, Saadatmand S, Nejad-Sattari T (2010) Effects of exogenous salicylic acid and nitric oxide on lipid peroxidation and antioxidant enzyme activities in leaves of Brassica napus L. under nickel stress. Sci Hortic 126:402-407

Khan MN, Mobin M, Abbas ZK, Siddiqui MH (2017) Nitric oxide-induced synthesis of hydrogen sulfide alleviates osmotic stress in wheat seedlings through sustaining antioxidant enzymes, osmolyte accumulation and cysteine homeostasis. Nitric Oxide 68:91-102

Kronzucker HJ, Siddiqi MY (1997) Conifer root discrimination against soil nitrate and the ecology of forest succession. Nature 385:59-61

Lee Y, Park J, Im K, Kim K, Lee J, Lee K et al (2006) Arabidopsis leaf necrosis caused by simulated acid rain is related to the salicylic acid signaling pathway. Plant Physiol Biochem 44:38-42

Li J, Yuan X, Ge L, Li Q, Li Z, Wang L et al (2020) Rhizosphere effects promote soil aggregate stability and associated organic carbon sequestration in rocky areas of desertification. Agric Ecosyst Environ 304:107126

Li C, Liu X, Meng M, Zhai L, Zhang B, Jia Z et al (2021) The use of Biolog Eco microplates to compare the effects of sulfuric and nitric acid rain on the metabolic functions of soil microbial communities in a subtropical plantation within the Yangtze River Delta region. Catena 198:105039

Liang C, Wang W (2013) Antioxidant response of soybean seedlings to joint stress of lanthanum and acid rain. Environ Sci Pollut Res 20:8182-8191

Liang C, Ge Y, Su L, Bu J (2015) Response of plasma membrane $\mathrm{H}^{+}$-ATPase in rice (Oryza sativa) seedlings to simulated acid rain. Environ Sci Pollut Res 22:535-545

Lindberg SE, Bredemeier M, Schaefer DA, Qi L (1990) Atmospheric concentrations and deposition of nitrogen and major ions in conifer forests in the United States and Federal Republic of Germany. Atmos Environ Part A 24:2207-2220

Liu TW, Niu L, Fu B, Chen J, Wu FH, Chen J et al (2013) A transcriptomic study reveals differentially expressed genes and pathways respond to simulated acid rain in Arabidopsis thaliana. Genome 56:49-60

Liu X, Zhang B, Zhao W, Wang L, Xie D, Huo W et al (2017) Comparative effects of sulfuric and nitric acid rain on litter decomposition and soil microbial community in subtropical plantation of Yangtze River Delta region. Sci Total Environ 601-602:669-678

Liu H, Ren X, Zhu J, Wu X, Liang C (2018a) Effect of exogenous abscisic acid on morphology, growth and nutrient uptake of rice (Oryza sativa) roots under simulated acid rain stress. Planta 248:647-659

Liu X, Fu Z, Zhang B, Zhai L, Meng M, Lin J et al (2018b) Effects of sulfuric, nitric, and mixed acid rain on Chinese fir sapling growth in Southern China. Ecotoxicol Environ Saf 160:154-161

Liu X, Zhao W, Meng M, Fu Z, Xu L, Zha Y et al (2018c) Comparative effects of simulated acid rain of different ratios of $\mathrm{SO}_{4}{ }^{2-}$ to $\mathrm{NO}_{3}{ }^{-}$on fine root in subtropical plantation of China. Sci Total Environ 618:336-346

Liu M, Huang X, Song Y, Tang J, Cao J, Zhang X et al (2019) Ammonia emission control in China would mitigate haze pollution and nitrogen deposition, but worsen acid rain. PNAS 116:7760-7765

Liu X, Li C, Meng M, Zhai L, Zhang B, Jia Z et al (2020) Comparative effects of the recovery from sulfuric and nitric acid rain on the soil enzyme activities and metabolic functions of soil microbial communities. Sci Total Environ 714:136788

Lv Y, Wang C, Jia Y, Wang W, Ma X, Du J et al (2014) Effects of sulfuric, nitric, and mixed acid rain on litter decomposition, soil microbial biomass, and enzyme activities in subtropical forests of China. Appl Soil Ecol 79:1-9

Ma Y, Wang B, Zhang R, Gao Y, Zhang X, Li Y et al (2019) Initial simulated acid rain impacts reactive oxygen species metabolism and photosynthetic abilities in Cinnamonum camphora undergoing high temperature. Ind Crop Prod 135:352-361

Ma S, Liu X, Jia Z, Meng M, Li C, Ren Q et al (2021) Response of Quercus acutissima foliage to different types of simulated acid rain. Atmosp Pollut Res 12:101112

Malagoli M, Canal AD, Quaggiotti S, Pegoraro P, Bottacin A (2000) Differences in nitrate and ammonium uptake between Scots pine and European larch. Plant Soil 221:1-3 
Mo J, Li D, Gundersen P (2008) Seedling growth response of two tropical tree species to nitrogen deposition in southern China. Eur J Forest Res 127:275-283

Ouyang X-J, Zhou G-Y, Huang Z-L, Liu J-X, Zhang D-Q, Li J (2008) Effect of simulated acid rain on potential carbon and nitrogen mineralization in forest soils. Pedosphere 18:503-514

Qiao F, Zhang XM, Liu X, Chen J, Hu WJ, Liu TW et al (2018) Elevated nitrogen metabolism and nitric oxide production are involved in Arabidopsis resistance to acid rain. Plant Physiol Biochem 127:238-247

Qiu Q, Wu J, Liang G, Liu J, Chu G, Zhou G et al (2015) Effects of simulated acid rain on soil and soil solution chemistry in a monsoon evergreen broadleaved forest in southern China. Environ Monit Assess 187:272

Ren X, Zhu J, Liu H, Xu X, Liang C (2018) Response of antioxidative system in rice (Oryza sativa) leaves to simulated acid rain stress. Ecotoxicol Environ Saf 148:851-856

Rollwagen BA, Zasoski RJ (1988) Nitrogen source effects on rhizosphere $\mathrm{pH}$ and nutrient accumulation by Pacific Northwest conifers. Plant Soil 105:79-86

Saleem M, Law AD, Sahib MR, Pervaiz ZH, Zhang Q (2018) Impact of root system architecture on rhizosphere and root microbiome. Rhizosphere 6:47-51

Sánchez-Pardo B, Fernández-Pascual M, Zornoza P (2012) Copper microlocalisation, ultrastructural alterations and antioxidant responses in the nodules of white lupin and soybean plants grown under conditions of copper excess. Environ Exp Bot 84:52-60

Shi J, Ohte N, Tokuchi N, Imamura N, Nagayama M, Oda T et al (2014) Nitrate isotopic composition reveals nitrogen deposition and transformation dynamics along the canopy-soil continuum of a suburban forest in Japan. Rapid Commun Mass Spectrom 28:2539-2549

Simpson CR, Gonzales J, Enciso J, Nelson SD, Sétamou M (2020) Root distribution and seasonal fluctuations under different grove floor management systems in citrus. Sci Hortic 272:109364

Sparks JP (2009) Ecological ramifications of the direct foliar uptake of nitrogen. Oecologia 159:1-13

Sun Z, Wang L, Zhou Q, Huang X (2013) Effects and mechanisms of the combined pollution of lanthanum and acid rain on the root phenotype of soybean seedlings. Chemosphere 93:344-352

Sun X, Wang Y, Li H, Yang X, Sun L, Wang X et al (2016) Organic acids in cloud water and rainwater at a mountain site in acid rain areas of South China. Environ Sci Pollut Res 23:9529-9539

Tang X, Lu Y, Fehrmann L, Forrester DI, Guisasola-Rodríguez R, Pérez-Cruzado C et al (2015) Estimation of stand-level aboveground biomass dynamics using tree ring analysis in a Chinese fir plantation in Shitai County, Anhui Province, China. New For 47:319-332

Thomas RQ, Canham CD, Weathers KC, Goodale CL (2009) Increased tree carbon storage in response to nitrogen deposition in the US. Nat Geosci $3: 13-17$

Wang X, Shi GX, Xu QS, Xu BJ, Zhao J (2007) Lanthanum- and cerium-induced oxidative stress in submerged Hydrilla verticillata plants. Russ J Plant Physiol 54:693-697

Wang P, Wang Z-K, Sun X-C, Mu X-H, Chen H, Chen F-J et al (2019) Interaction effect of nitrogen form and planting density on plant growth and nutrient uptake in maize seedlings. J Integr Agric 18:1120-1129

Wang J, Zhai L, Ma J, Zhang J, Wang GG, Liu X et al (2020) Comparative physiological mechanisms of arbuscular mycorrhizal fungi in mitigating saltinduced adverse effects on leaves and roots of Zelkova serrata. Mycorrhiza 30:341-355

Xia B, Sun Z, Wang L, Zhou Q, Huang X (2017) Analysis of the combined effects of lanthanum and acid rain, and their mechanisms, on nitrate reductase transcription in plants. Ecotoxicol Environ Saf 138:170-178

Xu RK, Ji GL (2001) Effects of $\mathrm{H}_{2} \mathrm{SO}_{4}$ and $\mathrm{HNO}_{3}$ on soil acidification and aluminum speciation in variable and constant charge soils. Water Air Soil Poll 129:33-43

Yao F-F, Ding H-M, Feng L-L, Chen J-J, Yang S-Y, Wang X-H (2016) Photosynthetic and growth responses of Schima superba seedlings to sulfuric and nitric acid depositions. Environ Sci Pollut Res 23:8644-8658

Yu B, Huang J-G, Ma Q, Guo X, Liang H, Zhang S et al (2019) Comparison of the effects of canopy and understory nitrogen addition on xylem growth of two dominant species in a warm temperate forest, China. Dendrochronologia 56:125604
Zhang Y, Bai S (2003) Effects of nitrogen forms on nutrient uptake and growth of trees. Chin J Appl Ecol 14:2044-2048

Zhang X-Q, Kirschbaum MUF, Hou Z, Guo Z (2004) Carbon stock changes in successive rotations of Chinese fir (Cunninghamia lanceolata (Lamb.) Hook) plantations. For Ecol Manag 202:131-147

Zhang JE, Ouyang Y, Ling DJ (2007) Impacts of simulated acid rain on cation leaching from the Latosol in south China. Chemosphere 67:2131-2137

Zhang Y, Tao Y, Zhang H, Wang L, Sun G, Sun X et al (2015) Effect of di-n-butyl phthalate on root physiology and rhizosphere microbial community of cucumber seedlings. J Hazard Mater 289:9-17

Zhang B, Bu J, Liang C (2016a) Root morphology and growth regulated by mineral nutrient absorption in rice roots exposed to simulated acid rain. Water Air Soil Pollut 227:457

Zhang X, Wang L, Zhou A, Zhou Q, Huang X (2016b) Alterations in cytosol free calcium in horseradish roots simultaneously exposed to lanthanum(III) and acid rain. Ecotoxicol Environ Saf 126:62-70

Zhang G, Liu D, He X, Yu D, Pu M (2017) Acid rain in Jiangsu province, eastern China: tempo-spatial variations features and analysis. Atmos Pollut Res 8:1031-1043

Zhang C, Yi X, Gao X, Wang M, Shao C, Lv Z et al (2020) Physiological and biochemical responses of tea seedlings (Camellia sinensis) to simulated acid rain conditions. Ecotoxicol Environ Saf 192:110315

Zhou T, Wang L, Sun X, Wang X, Chen Y, Rengel Z et al (2019) Light intensity influence maize adaptation to low $P$ stress by altering root morphology. Plant Soil 447:183-197

Zhou S, Zhang M, Chen S, Xu W, Zhu L, Gong S et al (2020) Acid resistance of Masson pine (Pinus massoniana Lamb.) families and their root morphology and physiological response to simulated acid deposition. Sci Rep 10:22066

\section{Publisher's Note}

Springer Nature remains neutral with regard to jurisdictional claims in published maps and institutional affiliations.

\section{Submit your manuscript to a SpringerOpen ${ }^{\circ}$ journal and benefit from:}

- Convenient online submission

- Rigorous peer review

- Open access: articles freely available online

- High visibility within the field

Retaining the copyright to your article

Submit your next manuscript at springeropen.com 